\title{
Application of Photo-Fenton Process for the Treatment of Kraft Pulp Mill Effluent
}

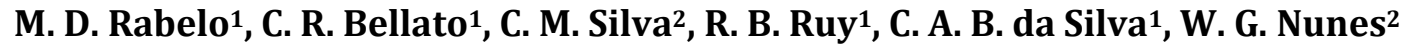 \\ ${ }^{1}$ Department of Chemistry, Federal University of Viçosa, Viçosa, Brazil \\ ${ }^{2}$ Department of Forest Engineering, Federal University of Viçosa, Viçosa, Brazil \\ Email: bellato@ufv.br, mudado@ufv.br
}

Received 28 August 2014; revised 15 September 2014; accepted 28 September 2014

Copyright (C) 2014 by authors and Scientific Research Publishing Inc.

This work is licensed under the Creative Commons Attribution International License (CC BY).

http://creativecommons.org/licenses/by/4.0/

(c) (i) Open Access

\section{Abstract}

The present work evaluated the use of photo-Fenton process for the treatment of kraft pulp mill effluent. The photo-Fenton best operating conditions, such as $\mathrm{pH}$, concentration, and $\mathrm{H}_{2} \mathrm{O}_{2}: \mathrm{Fe}^{2+}$ ratio were evaluated. The efficiency of the treatment was measured by $\operatorname{COD}$ (chemical oxygen demand) removal. The results showed that the optimum $\mathrm{pH}$ for the photo-Fenton process was equal to 3. The increase in $\mathrm{H}_{2} \mathrm{O}_{2}$ application resulted in an efficiency increase of the photo-Fenton process, although this was not a directly proportional relation. For most cases, the $\mathrm{H}_{2} \mathrm{O}_{2}$ : $\mathrm{Fe}^{2+}$ proportion of 100:1 yielded the best results for $C O D$ removal. Solar radiation was more efficient than artificial UV to the COD removal. During the treatment the organic matter of the effluent was more oxidized than mineralized, showing a higher removal of $C O D$ than $B O D$ (biochemical oxygen demand) and TOC (total organic carbon), respectively. So, photo-Fenton process increased the BOD/ $C O D$ ration but decreased the $B O D / T O C$ ratio.

\section{Keywords}

COD, ECF Bleached Kraft Pulp, Photo-Fenton

\section{Introduction}

Biological treatment processes are commonly used to treat pulp mill effluents and, in some cases, are not enough to meet regulations. In part, this is due to a fraction of recalcitrant organic matter present in the effluent, which is inert to biological oxidation.

An alternative to increase the removal of recalcitrant organic matter would be a pretreatment of this material, changing it into biodegradable compounds. The technology known as advanced oxidation processes $(A O P)$ has been tested for the oxidation of some types of organic compounds, such as chlorinated phenols, being able to 
completely convert them into $\mathrm{CO}_{2}$ or partially oxidize them [1]-[3].

This type of treatment may also fractionate complex molecules of high molecular mass into simpler intermediate compounds, such as acetic, maleic, and oxalic acids, acetone and chloroform. These new formed compounds are part of the bioenergetic cycle of living organisms and, therefore, they are compatible with the biological treatment [4].

The AOP constitute a set of techniques based on the generation of the free radical $(\cdot \mathrm{OH})$, in sufficient quantity to reach the oxidative degradation of the organic contaminants in water and wastewater [5]. The radical $\bullet \mathrm{OH}$ has a high potential for reduction, making it effective in oxidizing organic compounds.

Although several studies are being carried out, evaluating the oxidation of recalcitrant compounds in synthetic effluents, the application of the photo-Fenton process for the treatment of bleached kraft pulp mill effluent was not yet fully studied. Therefore, the main objective of this research was to evaluate the application of this process to the treatment of bleached kraft pulp mill effluent. Specific objectives were: i) to find the best operating $\mathrm{pH}$; ii) to optimize the dosage and find the best $\mathrm{H}_{2} \mathrm{O}_{2}: \mathrm{Fe}^{+2}$ ratio; iii) to evaluate the source of radiation (solar and artificial); iv) to evaluate the efficiency of photo-Fenton reaction in removing organic contaminants from the industrial effluent.

\section{Material and Methods}

\subsection{Effluents}

The effluent used was collected at a bleached eucalyptus kraft pulp mill where $D(E O P) D D$ bleaching sequence is used. The final effluent is a mixture of acid and alkaline filtrates from the bleaching plant and wastewater from other areas of the plant.

\subsection{Photo-Fenton Treatment}

The optimum $\mathrm{pH}$ to treat the effluent was established through preliminary testing to be in the range of 2.5 to 5.0 . The treatments were carried out at two sources of radiation: solar and artificial. A 9-W black light lamp, with emission spectrum in the region of the near-to-visible ultraviolet (UVA) was used as source of artificial radiation. The experimental unit for the treatments carried out under sunlight consisted of four identical chemical photoreactors, with $0.043 \mathrm{~m}^{2}$ of superficial area exposed to sunlight. A volume of $250 \mathrm{ml}$ of effluent were treated in each photoreactor. The effluent layer thickness of $0.7 \mathrm{~cm}$ was used.

Fenton reaction was promoted by adding hydrated ferrous sulphate $\left(\mathrm{Fe}_{2} \mathrm{SO}_{4} \cdot 7 \mathrm{H}_{2} \mathrm{O}\right)$ and stock solution of $\mathrm{H}_{2} \mathrm{O}_{2}$ to the effluent. The mixture was homogenized during the whole treatment by agitating with a magnetic bar. Each treatment lasted 120 minutes, all of them having been carried out between noon and 2 p.m. at ambient temperature.

The consumption of $\mathrm{H}_{2} \mathrm{O}_{2}$ during Fenton reaction was evaluated in parallel. For this purpose, a fifth treatment was required to be carried out concomitantly, by keeping the same conditions of the other four repetitions, but using a photoreactor with capacity for a higher volume of effluent $(1250 \mathrm{ml})$. The concentration of $\mathrm{H}_{2} \mathrm{O}_{2}$ was determined by iodometry.

The treatments that used a black light lamp as source of radiation were carried out on a laboratory bench apparatus. The conditions and methods adopted for these treatments were analogous to those described for the treatments under solar radiation, except for the configuration of the photoreactor used. A configuration similar to those described by other authors [3] was used for these treatments.

A peristaltic pump (Gilson, Milliplus 3), with flow adjusted so as to apply the whole dosage of reagent in the course of 60 minutes, was used for the treatments with continuous addition of reagents. The dosage of $\mathrm{H}_{2} \mathrm{O}_{2}$ and $\mathrm{Fe}^{2+}$ in each treatment corresponded to 500 and $50 \mathrm{mg} \cdot \mathrm{l}^{-1}$, respectively.

\subsection{Chemical Analyses}

The analyses of $\mathrm{pH}, \mathrm{COD}, \mathrm{BOD}$, colour, total phenols, total nitrogen, total phosphorus, and chlorides, were conducted in accordance with the Standard Methods for the Examination of Water and Wastewater [6].

For the analysis of $T O C$, the samples were filtered in qualitative filter paper (quick filtration, black stripe), the pH having been adjusted thereafter to a range of 2 to 3 with 20\% sulphuric acid. Later, TOC was analyzed in a TOC-5000A SHIMADZU apparatus according to the manufacturer's manual. The analyses of AOX (adsorbable 
organic halogens) of the effluents were done in a Euroglas ECS 1600 equipment in accordance with SCAN standard [7].

\section{Results and Discussion}

\subsection{Effluent Characterization}

The effluent used in the study showed typical characteristics of eucalyptus kraft pulp mill effluents (Table 1), as the high chloride content and the high ratio between organic matter (BOD or $C O D)$ and the nutrients nitrogen and phosphorus. The $\mathrm{pH}$ near the neutral and the $B O D / C O D$ ratio above 0.4 indicates biological treatability.

\subsection{Selection of the Best $\mathrm{pH}$ for the Photo-Fenton Process}

The mixture of all currents of sectorial effluents of a mill generates a final effluent, the $\mathrm{pH}$ of which normally ranges from 5 to 8 , which is more suitable for the biological treatment, but incompatible with the photo-Fenton reaction (Figure 1).

The difference between the $\mathrm{pH}$ of the final effluent and the optimum $\mathrm{pH}$ found for the photo-Fenton process is an inconvenience for applying this technology. In operating conditions it would require large amounts of acid to lower the $\mathrm{pH}$ of the effluents to the optimum value for treatment.

\subsection{Sources of Radiation for the Photo-Fenton Process}

The continuous treatment of effluents by means of the photo-Fenton process requires the use of an artificial source of light for night periods. However, once the $\mathrm{pH}$ of the effluents is adjusted and the dosages of reagents are optimized, the levels of removal of $C O D$ reached in the conventional (biological) treatments can be attained and even surpassed by the photo-Fenton process, under solar or artificial radiation (Figure 2).

The concentrations of $\mathrm{H}_{2} \mathrm{O}_{2}$ at the beginning of the treatments of the sets of Experiments 1, 2, 3, 4, 5, and 6 were $60,80,100,500,1000$, and $2000 \mathrm{mg} \cdot \mathrm{l}^{-1}$, respectively. The initial COD of the effluents ranged from 920 to $1190 \mathrm{mg} \cdot \mathrm{l}^{-1}$. The error bar shown in each column represents the standard deviation around an average of 4 repetitions. For each set of experiments, the averages followed by at least the same letter do not differ from each other at the level of a $5 \%$ probability by Tukey test. The average solar luminous intensity accumulated during the treatments was $475 \pm 188 \mathrm{~W} \cdot \mathrm{m}^{-2}$.

For the experiments carried out under solar radiation it became evident that the treatments employing 100:1 $\left(\mathrm{H}_{2} \mathrm{O}_{2}: \mathrm{Fe}^{2+}\right)$ ratio distinguished themselves from the remaining ones. Except for the results obtained for Experiment 1 , the treatments that used 100:1 ratio presented the best performance in terms of COD removal. It is well-known that radicals $\bullet \mathrm{OH}$ generated in Fenton reaction react more rapidly with $\mathrm{Fe}^{2+}$ (rate constant $=3.0 \times$ $10^{8} \mathrm{l} \cdot \mathrm{mol}^{-1} \cdot \mathrm{s}^{-1}$ ) ions than with $\mathrm{H}_{2} \mathrm{O}_{2}$ (rate constant $=2.7 \times 10^{7} \mathrm{l} \cdot \mathrm{mol}^{-1} \cdot \mathrm{s}^{-1}$ ). Thus, it is probable that from the treatments carried out with the same concentration of hydrogen peroxide those having used lower iron loads, that is, 100:1, were less impaired by this type of deleterious reaction. On the other hand, the photoreduction of

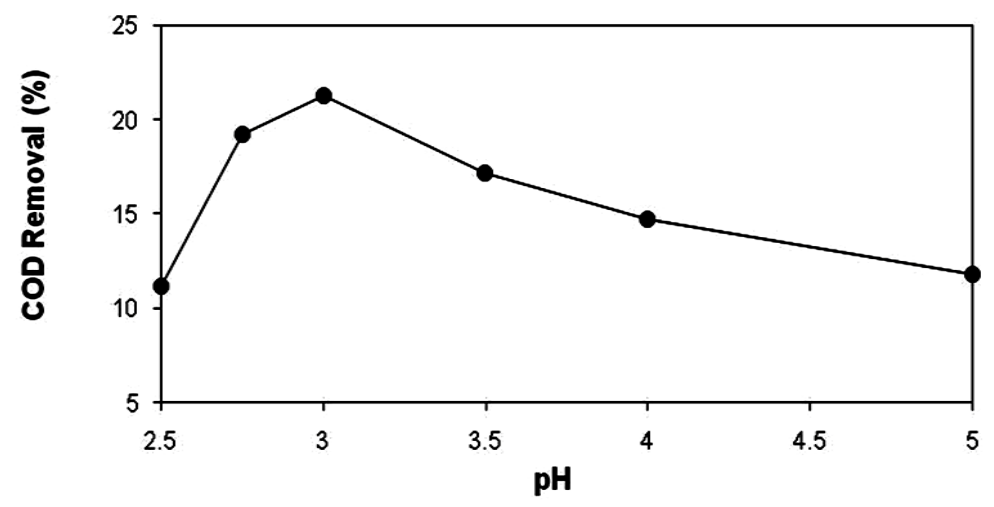

Figure 1. Effect of pH on removal of organic matter $(C O D)$ from the effluent through the photo-Fenton process. $\left[\mathrm{H}_{2} \mathrm{O}_{2}\right]=100 \mathrm{mg} \cdot \cdot^{-1} ;\left[\mathrm{Fe}^{2+}\right]=20 \mathrm{mg} \cdot \mathrm{l}^{-1}$; and initial $C O D=1197 \mathrm{mg} \cdot \mathrm{l}^{-1}$. 


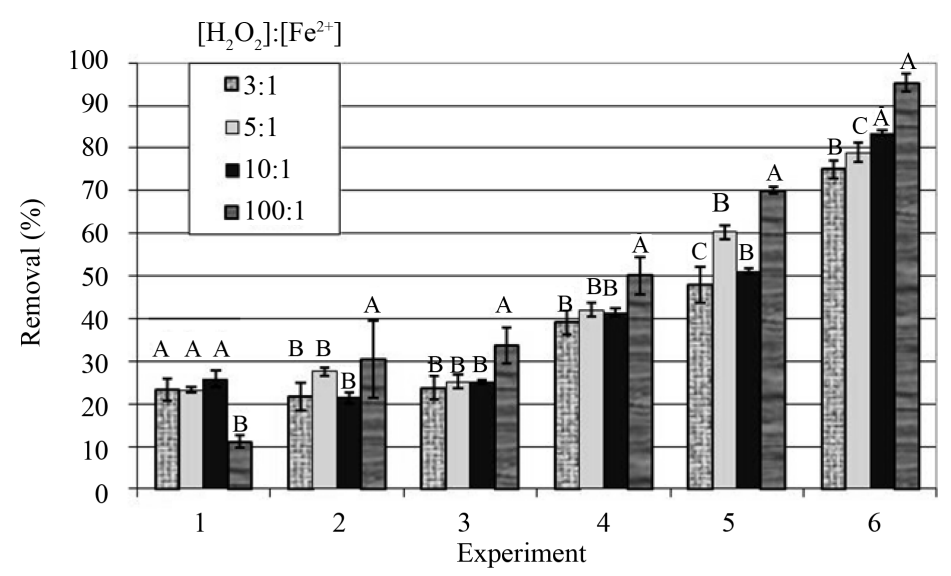

(a)

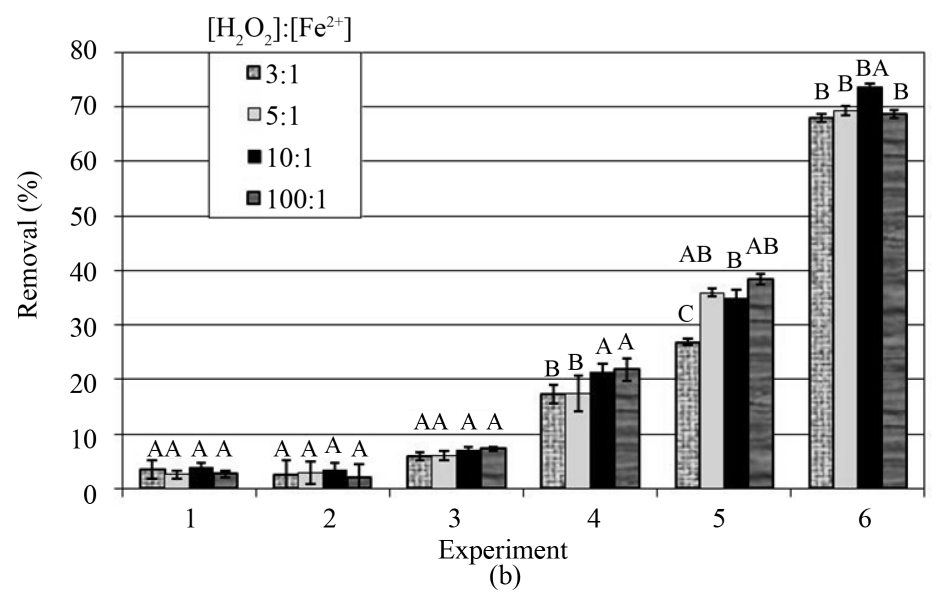

Figure 2. Removal of $C O D$ from the effluents treated by the photo-Fenton process, using solar (a) and ultraviolet light (b).

Table 1. Results of the physicochemical effluent characterization.

\begin{tabular}{|c|c|c|}
\hline Parameter & $1^{\text {st }}$ sampling* $\left(\mathrm{mg} \cdot 1^{-1}\right)$ & $2^{\text {nd }}$ sampling $^{*}\left(\mathrm{mg} \cdot \mathrm{l}^{-1}\right)$ \\
\hline Chloride & $420 \pm 26$ & $486 \pm 32$ \\
\hline Colour & $253 \pm 19$ & $238 \pm 19$ \\
\hline$B O D_{5}$ & $694 \pm 28$ & $576 \pm 75$ \\
\hline$C O D$ & $1235 \pm 34$ & $1204 \pm 13$ \\
\hline$N$ total & $0.76 \pm 0.04$ & $0.66 \pm 0.06$ \\
\hline$P$ total & $1.36 \pm 0.01$ & $1.37 \pm 0.03$ \\
\hline$p H$ & 7.4 & 7.2 \\
\hline
\end{tabular}

*Average of 3 repetitions \pm standard deviation.

$\mathrm{Fe}^{3+}$ by sunlight maintains the concentration of $\mathrm{Fe}^{2+}$ in the reactive medium, guaranteeing the efficiency of the photo-Fenton process even in treatments with low initial concentration of ferrous ions [8].

These results disclose another particularly important aspect for a possible industrial application, since high iron loads, besides making the process more expensive, cause a thin sludge of iron hydroxide precipitates to form during neutralization of the effluent $\mathrm{pH}$.

Previous works were carried out, comparing experiments at different initial concentrations of $\mathrm{Fe}^{2+}$. Such 
works revealed that higher concentrations of $\mathrm{Fe}^{2+}$ at the beginning of Fenton reaction imply higher velocity of degradation of the organic contaminants, but in some cases without appreciably increasing the efficiency of the process [2] [8]-[10]. Higher concentrations of $\mathrm{Fe}^{2+}$ at the beginning of the reaction favour the formation of radicals $\bullet \mathrm{OH}$, which explains the higher velocity of degradation at the beginning of the reaction. On the other hand, higher concentrations of $\mathrm{Fe}^{2+}$ also increase the deleterious effect of this metal on the free radicals, contributing to reduce the efficiency of the photo-Fenton process.

Another important aspect was the high removal of $C O D$ reached in the Experiment 6, which attained $95.4 \%$ in the treatment that used the 100:1 ratio. In that treatment, the $C O D$ of the effluent was reduced to $43 \mathrm{mg} \cdot \mathrm{l}^{-1}$, a value far below the emission standards stipulated by rigorous environmental legislations. These observations corroborate the potential of $A O P$ for the treatment of effluents.

In general, the treatments carried out with artificial irradiation were less efficient than those performed using solar irradiation, as far as the percentages of reduction in the COD of the effluents are concerned. As most experimental conditions were similar, the main explanation for such behaviour is that the black light lamp does not present the same efficiency as sunlight, as far as the photoreduction in $\mathrm{Fe}^{3+}$ is concerned. Furthermore, another factor that may have contributed to such results was the thickness of the effluent layer. A thicker layer may make it more difficult for the UV rays to penetrate the full extent of the sample, restricting photoreduction of $\mathrm{Fe}^{3+}$ to the most superficial layers of the liquid.

When statistically analyzing the results shown in the graphs of Figure 2, it is possible to conclude that the removal of $C O D$ increases by a lower proportion than the increase in the initial dosage of hydrogen peroxide. As the concentration of reagents $\left(\mathrm{H}_{2} \mathrm{O}_{2}\right.$ and $\left.\mathrm{Fe}^{2+}\right)$ is increased, the harmful effects are intensified, since $\mathrm{H}_{2} \mathrm{O}_{2}$ reacts with radicals $\bullet \mathrm{OH}$, competing with the organic matter oxidation [11] [12].

Figure 3 shows the decrease in concentration of $\mathrm{H}_{2} \mathrm{O}_{2}$ during effluent treatment. The initial concentration of $\mathrm{H}_{2} \mathrm{O}_{2}$ in the treatments was equal to: a) $60 \mathrm{mg} \cdot 1^{-1}$, b) $80 \mathrm{mg} \cdot \mathrm{l}^{-1}$, c) $100 \mathrm{mg} \cdot \mathrm{l}^{-1}$, d) $500 \mathrm{mg} \cdot \mathrm{l}^{-1}$, e) $1000 \mathrm{mg} \cdot \mathrm{l}^{-1}$, and f) $2000 \mathrm{mg} \cdot l^{-1}$. The ratios 3:1, 5:1, 10:1, and 100:1 between reagents $\mathrm{H}_{2} \mathrm{O}_{2}$ and $\mathrm{Fe}^{2+}$, adopted in each treatment, are shown in the area of each graph.

The decrease in concentration of $\mathrm{H}_{2} \mathrm{O}_{2}$ as a function of the treatment time reveals that the most pronounced consumption of this reagent occurs during the first minutes of reaction, except for the treatments having used the 100:1 proportion. In these treatments, the consumption of $\mathrm{H}_{2} \mathrm{O}_{2}$ is well-distributed during the whole reaction time, probably because the lower availability of ferrous ions (required to form the radicals $\bullet \mathrm{OH}$ in the reactive medium reduces the velocity of decomposition of the hydrogen peroxide. In the treatments using Fenton reagent in the proportions of 3:1, 5:1, and 10:1, for which a quick consumption of $\mathrm{H}_{2} \mathrm{O}_{2}$ was observed, it is probable that the generation of radicals $\bullet \mathrm{OH}$ and consequently the organic matter degradation mainly occur at the beginning of the treatment.

From the operating point of view, this is a further important aspect, as reduction in effluent treatment time can be achieved by increasing the dosage of $\mathrm{Fe}^{2+}$ at the beginning of the treatment. Thus, for the design of an effluent treatment plant by means of the photo-Fenton process the hydraulic retention time should be determined as a function of the ratio between reagents $\mathrm{H}_{2} \mathrm{O}_{2}$ and $\mathrm{Fe}^{2+}$ to be used.

\subsection{Effluent Treatment Efficiency}

A more complete evaluation of the performance of the photo-Fenton process was carried out as soon as the most suitable ratio (100:1) between the dosages of reagents $\mathrm{H}_{2} \mathrm{O}_{2}$ and $\mathrm{Fe}^{2+}$ was defined.

The results showed in Table 2 indicate that the removal of $C O D$ by the photo-Fenton process increased as the dosages of reagents $\mathrm{H}_{2} \mathrm{O}_{2}$ and $\mathrm{Fe}^{2+}$ increased. Nevertheless, the increase in $C O D$ removal did not reflect the same proportion of the increase in the initial dosage of the reagents.

The removal of $C O D$ surpassed removals of $B O D, T O C$, and AOX. Apparently inconsistent, this result can be understood, since during the photo-Fenton reaction a good part of the organic matter is not completely mineralized (converted into $\mathrm{CO}_{2}$ ). A part of it turns into partially oxidized compounds, which reduces $\mathrm{COD}$, and/or is converted into simpler subproducts, such as the carboxylic and formic acids and aldehydes, which are, on the other hand, more biodegradable [2] [13]. The results also show that BOD/TOC ratio, understood as the biodegradability per carbon atom, decreased after effluent treatment, which reinforces the idea that the organic matter was modified (partially oxidized), rather than mineralized.

The $B O D / C O D$ ratio of the effluents increased after two out of the three treatments, characterizing an indica- 


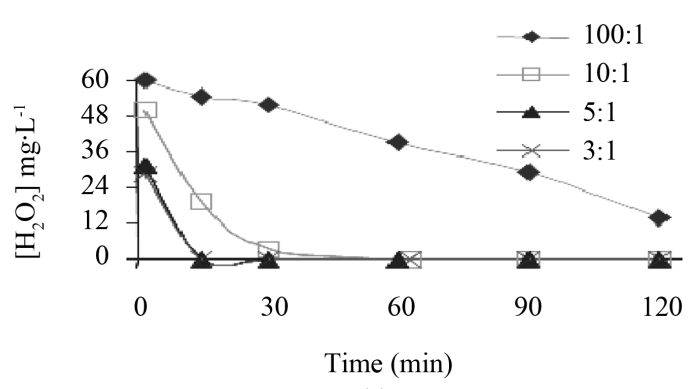

(a)

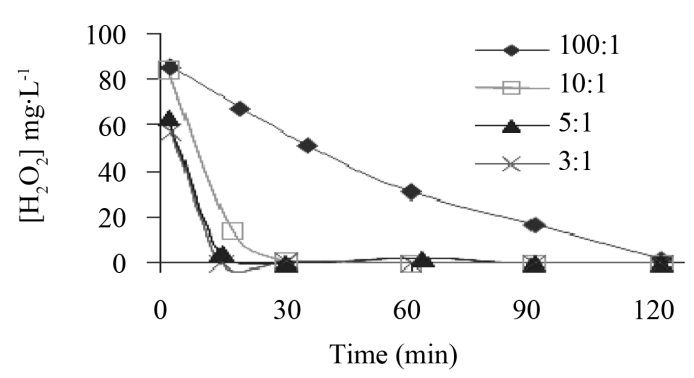

(c)

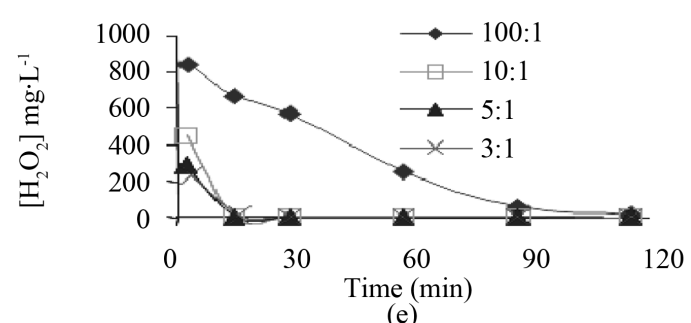

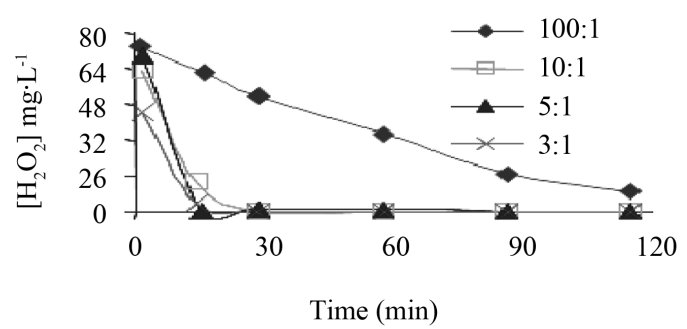

(b)

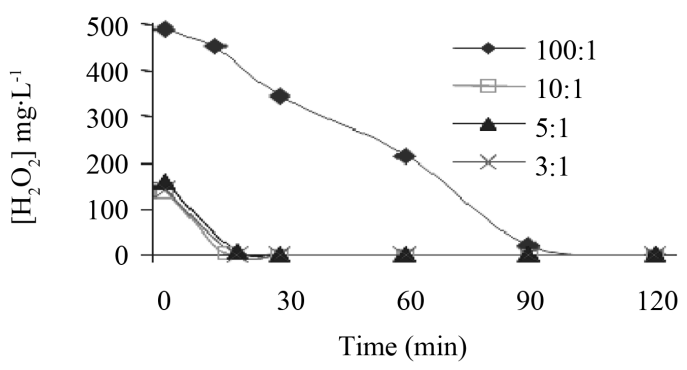

(d)

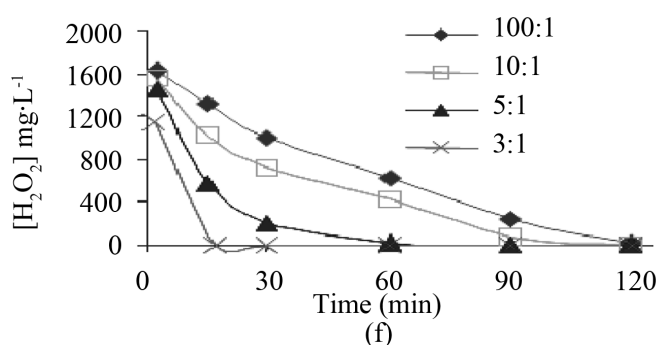

Figure 3. Decrease of the concentration of $\mathrm{H}_{2} \mathrm{O}_{2}$ during effluent treatment. The initial concentrations of $\mathrm{H}_{2} \mathrm{O}_{2}$ were: (a) 60 $\mathrm{mg} \cdot \mathrm{l}^{-1}$; (b) $80 \mathrm{mg} \cdot \mathrm{l}^{-1}$; (c) $100 \mathrm{mg} \cdot \mathrm{l}^{-1}$; (d) $500 \mathrm{mg} \cdot \mathrm{l}^{-1}$; (e) $1000 \mathrm{mg} \cdot \mathrm{l}^{-1}$; and (f) $2000 \mathrm{mg} \cdot \mathrm{l}^{-1}$.

Table 2. Removal of $C O D, B O D$, TOC, and $A O X$ from effluents treated by using 100:1 ratio between reagents $\mathrm{H}_{2} \mathrm{O}_{2}$ and $\mathrm{Fe}^{2+}$.

\begin{tabular}{|c|c|c|c|c|c|c|}
\hline & $\begin{array}{c}C O D \\
\mathrm{mg} \cdot 1^{-1}\end{array}$ & $\begin{array}{l}B O D_{5} \\
\mathrm{mg} \cdot 1^{-1}\end{array}$ & $\begin{array}{c}\text { TOC } \\
\mathrm{mg} \cdot 1^{-1}\end{array}$ & $\begin{array}{c}A O X \\
\mathrm{mg} \cdot l^{-1}\end{array}$ & $B O D_{5} / C O D$ & BOD/TOC \\
\hline Raw Effluent & 1246 & 502 & 457 & 10.7 & 0.40 & 1.10 \\
\hline Treated Effluent $\left[\mathrm{H}_{2} \mathrm{O}_{2}\right]=80 \mathrm{mg} \cdot \mathrm{l}^{-1}$ & 988 & 441 & 407 & 9.8 & 0.45 & 1.08 \\
\hline Removal (\%) & 20.7 & 18.1 & 11.0 & 8.3 & - & - \\
\hline Treated Effluent $\left[\mathrm{H}_{2} \mathrm{O}_{2}\right]=500 \mathrm{mg} \cdot \mathrm{l}^{-1}$ & 816 & 323 & 384 & 9.1 & 0.40 & 0.84 \\
\hline Removal (\%) & 34.5 & 35.7 & 16.0 & 14.4 & - & - \\
\hline Treated Effluent $\left[\mathrm{H}_{2} \mathrm{O}_{2}\right]=1000 \mathrm{mg} \cdot \mathrm{l}^{-1}$ & 476 & 272 & 345 & 8.6 & 0.57 & 0.79 \\
\hline Removal (\%) & 61.8 & 45.8 & 24.4 & 19.1 & - & - \\
\hline
\end{tabular}

tion of increase in biological treatability of the effluent. This aspect of the photo-Fenton process suggests that there is the potential to improve the performance of a subsequent biological treatment.

The reductions in $A O X$ and TOC are in the same range, which means to say that the intermediate compounds formed are still chlorinated. 


\section{Conclusions}

The high removals of $C O D$, obtained in some experiments, show that the photo-Fenton process has the technical potential to be used in the treatment of pulp mill effluents.

The $\mathrm{pH} 3$ was the optimum for application of the photo-Fenton process to the treatment of effluents from the bleached kraft pulp industry. At this $\mathrm{pH}$, the experiments carried out with initial ratio of 100:1 between the concentrations of reagents $\mathrm{H}_{2} \mathrm{O}_{2}$ and $\mathrm{Fe}^{2+}$ presented the highest removals of $C O D$. The removal of $C O D$ by the photo-Fenton process increases as the dosages of reagents $\mathrm{H}_{2} \mathrm{O}_{2}$ and $\mathrm{Fe}^{2+}$ are increased. Nevertheless, the increase in $C O D$ removal does not reflect the same proportion of the increase in the initial dosage of the reagents. The treatments carried out under sunlight presented higher reductions in $C O D$ than those performed with artificial radiation. Treatments carried out under sunlight, with application of 2000 and $20 \mathrm{mg} \cdot \mathrm{l}^{-1}$ of $\mathrm{H}_{2} \mathrm{O}_{2}$ and $\mathrm{Fe}^{2+}$, respectively, removed over $95 \%$ of $C O D$ from the effluents. For the treatments performed with artificial irradiation, the highest reduction (73.5\%) in COD was noticed when 2000 and $200 \mathrm{mg} \cdot \mathrm{l}^{-1}$ of $\mathrm{H}_{2} \mathrm{O}_{2}$ and $\mathrm{Fe}^{2+}$, respectively, were used.

Experiments carried out under sunlight showed that removal of $B O D, T O C$, and $A O X$ also increases as the dosages of Fenton reagent are increased, but in the same way as with regard to $C O D$, it does not reflect the same proportion.

During the chemical treatment, the organic matter present in the effluents was oxidized, rather than mineralized, higher percentage removals of $C O D, B O D$, and TOC, respectively, having been observed. For this reason, the photo-Fenton process increased $B O D / C O D$ ratio, but reduced $B O D / T O C$ ratio.

\section{Acknowledgments}

The authors would like to thank Capes, FAPEMIG, CNPq and Cenibra.

\section{References}

[1] Titus, M.P., Molina, V.G., Banos, M.A., Gimenez, J. and Santiago, E. (2004) Degradation of Chlorophenols by Means of Advanced Oxidation Processes: A General Review. Applied Catalysis B: Environmental, 47, 219-256. http://dx.doi.org/10.1016/j.apcatb.2003.09.010

[2] Katsumata, H., Kawabe, X., Kaneco, S., Suzuki, T. and Ohta, K. (2004) Degradation of BispHenol A in Water by the Photo-Fenton Reaction. Journal of Photochemistry and Photobiology A, 162, 297-305. http://dx.doi.org/10.1016/S1010-6030(03)00374-5

[3] Ghaly, M.Y., Hartel, G., Mayer, R. and Roland, H. (2001) Photochemical Oxidation of P-Chlorophenol by UV/H2O2 and Photo-Fenton Process. A Comparative Study. Waste Management, 21, 41-47. http://dx.doi.org/10.1016/S0956-053X(00)00070-2

[4] Bigda, R.J. (1995) Consider Fenton's Chemistry for Wastewater Treatment. Chemical Engineering Progress, 91, 62-66.

[5] Legrini, O., Oliveiros, E. and Braun, M. (1993) Photochemical Processes for Water Treatment. Chemical Reviews, 93, 671-698. http://dx.doi.org/10.1021/cr00018a003

[6] (1998) Standard Methods for the Examination of Water and Wastewater. 20th Edition, American Public Health Association/American Water Works Association/Water Environment Federation, Washington DC.

[7] Scan: Scandinavian Pulp, Paper and Board (1994) Scantest Standard. Distribuition: Secretariat, Scandinavina Pulp, Paper and Board Test Committee, Stockholm, August 1994.

[8] Kavitha, V. and Palnivelu, K. (2003) The Role of Ferrous ion in Fenton and Photo-Fenton Processes for the Degradation of Phenol. Chemosphere, 55, 1235-1243. http://dx.doi.org/10.1016/j.chemosphere.2003.12.022

[9] Pérez, M., Torrades, F., Hortal, J.A.G., Domenech, X. and Peral, J. (2002) Removal of Organic Contaminants in Paper Pulp Treatment Effluents under Fenton and Photo-Fenton Conditions. Applied Catalysis B: Environmental, 36, 63-74. http://dx.doi.org/10.1016/S0926-3373(01)00281-8

[10] Moraes, J.E.F., Silva, D.N., Quina, F.H., Filho, O.C. and Nascimento, C.A.O. (2004) Utilization of Solar Energy in the Photodegradation of Gasoline in Water and of Oil-Field-Produced Water. Environmental Science Technology, 38, 3746-3751. http://dx.doi.org/10.1021/es034701i

[11] Rodriguez, M., Sarria, V., Esplugas, S. and Pulgarin, C. (2002) Photo-Fenton Treatment of a Biorecalcitrant Wastewater Generated in Textile Activities. Journal of Photochemistry and Photobiology A: Chemistry, 151, 129-135. http://dx.doi.org/10.1016/S1010-6030(02)00148-X 
[12] Torrades, F., Pérez, M., Mansilla, H.D. and Peral, J. (2003) Experimental Design of Fenton and Photo-Fenton Reactions for the Treatment of Cellulose Bleaching Effluents. Chemosphere, 53, 1211-1220. http://dx.doi.org/10.1016/S0045-6535(03)00579-4

[13] Neyens, E. and Baeyens, J. (2003) A Review of Classic Fenton’s Peroxidation as an Advanced Oxidation Technique. Journal of Hazardous Materials, B98, 33-50. http://dx.doi.org/10.1016/S0304-3894(02)00282-0 
Scientific Research Publishing (SCIRP) is one of the largest Open Access journal publishers. It is currently publishing more than 200 open access, online, peer-reviewed journals covering a wide range of academic disciplines. SCIRP serves the worldwide academic communities and contributes to the progress and application of science with its publication.

Other selected journals from SCIRP are listed as below. Submit your manuscript to us via either submit@scirp.org or Online Submission Portal.
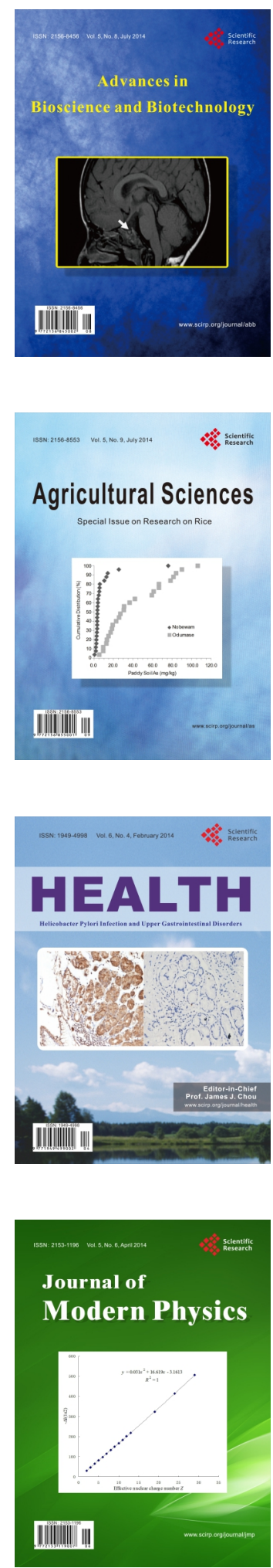
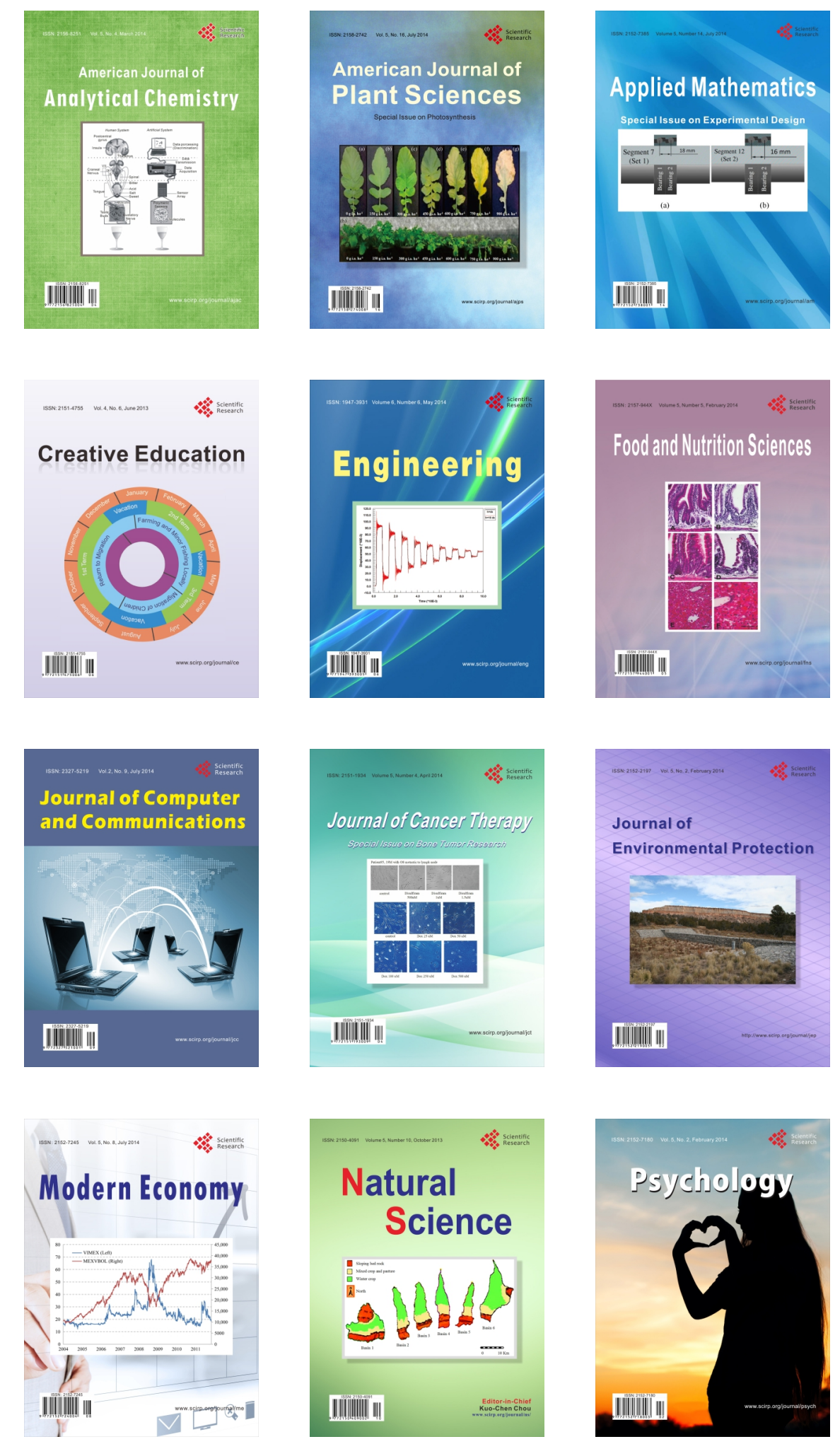